\title{
ITPKA expression is a novel prognostic factor in hepatocellular carcinoma
}

\author{
Jianbiao $\mathrm{Li}^{1 \dagger}$, Ying-Hui Zhu ${ }^{1+}$, Pinzhu Huang ${ }^{3}$, Baozhu Zhang ${ }^{1}$, Jian Sun ${ }^{1 *}$ and Xin-Yuan Guan ${ }^{1,2^{*}}$
}

\begin{abstract}
Background: Inositol-1,4,5-trisphosphate-3-kinase-A (ITPKA) has recently been found to be implicated in the tumor progression of various cancers. However, the expression and the prognostic value of ITPKA in hepatocellular carcinoma (HCC) remains unexplored. The aim of this study is to investigate the clinical significance of ITPKA expression in HCC.

Methods: We determined the expression level of ITPKA in 135 cases of HCC tissues and the matched adjacent nontumorous tissues by quantitative real-time RT-PCR. The correlation between ITPKA expression and prognosis of HCC patients was further evaluated by univariate and multivariate analysis. Multivariate analysis of the prognostic factors was performed with Cox proportional hazards model.

Results: Up-regulation of ITPKA occurred in $48.9 \%$ of primary HCCS compared with their nontumor counterparts $(P<0.001)$. In addition, high expression of ITPKA was significantly associated with vascular invasion $(P=0.001)$ and TNM stage $(P=0.005)$. Kaplan-Meier analysis showed that the 5 -year overall survival $(O S)$ and relapse-free survival (RFS) rate in the group with high expression of ITPKA is poorer than that in low expression group (32.2 and $26.8 \%$ versus 59.2 and $57.7 \%$ ). Univariate and multivariate analyses revealed that ITPKA was an independent prognostic factor for OS and RFS. Moreover, Stratified analysis revealed that its prognostic significance still existed within the subgroup of patients with early clinical stage (TNM stage I) or normal serum AFP level ( $\leq 25 \mu \mathrm{g} / \mathrm{L})$.
\end{abstract}

Conclusion: Our data indicated that ITPKA expression was significantly up-regulated in HCC and could serve as a potential novel prognostic biomarker for HCC patients after surgery.

\section{Background}

Hepatocellular carcinoma (HCC) is a highly lethal cancer, which has been ranked as the fifth most common malignancy and the third leading cause of cancer-related mortality worldwide [1-4]. Despite of the tremendous progress in diagnosis and multimodality treatment in the past decades, the prognosis of HCC patients remains grim, mainly because of its high recurrent and metastatic rate [5]. To date, numerous studies have identified a mass of dysregulated molecular events involved in liver carcinogenesis, which cover a wide range of genes with various functions. However, the biomarkers for $\mathrm{HCC}$ remain unsatisfactory in terms of high-risk population

\footnotetext{
* Correspondence: sunjian@sysucc.org.cn; xyguan@hkucc.hku.hk †Equal contributors

'Sun Yat-sen University Cancer Center, State Key Laboratory of Oncology in South China, Collaborative Innovation Center for Cancer Medicine, Block 2, Room 708, 651 Dongfeng East Road, Guangzhou 510060, China Full list of author information is available at the end of the article
}

screening, clinical diagnosis and prognosis, and evaluation of treatment efficiency. Therefore, it is imperative to identify and characterize novel biomarkers for this disease.

With the advent of high-throughput sequencing technologies in recent years, transcriptome sequencing (RNA-Seq) has been a powerful tool for gene expression profiling in the study of cancer. Recently, our group exploited a RNA-Seq to delineate differential gene expression in ten pairs of $\mathrm{HCC}$ and nontumor clinical samples. Overexpression of inositol-1,4,5-trisphosphate3-kinase-A (ITPKA) was observed in all ten HCC tumor tissues compared with their matched nontumoral counterparts. ITPKA gene, which is located in $15 \mathrm{q} 15$, encodes a predicted 461 amino acid polypeptide. Under physiological conditions, ITPKA is only identified in neurons and testis [6]. It is one of the three inositol trisphosphate 3-kinases (ITPKs) isoforms (A, B and C) that catalyse the phosphorylation of the second messenger inositol

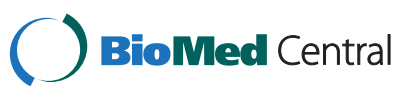

(c) 2015 Li et al. Open Access This article is distributed under the terms of the Creative Commons Attribution License (http://creativecommons.org/licenses/by/4.0), which permits unrestricted use, distribution, and reproduction in any medium, provided the original work is properly credited. The Creative Commons Public Domain Dedication waiver (http://creativecommons.org/publicdomain/zero/1.0/) applies to the data made available in this article, unless otherwise stated. 
1,4,5-trisphosphate $\left(\operatorname{Ins}(1,4,5) \mathrm{P}_{3}\right)$ to inositol 1, 3, 4, 5tetrakisphosphate $\left(\operatorname{Ins}(1,3,4,5) \mathrm{P}_{4}\right)$, and thus regulate Ins $(1,4,5) \mathrm{P}_{3}$-induced calcium $\left(\mathrm{Ca}^{2+}\right)$ signals $[7,8]$. Independent of this catalytic activity, ITPKA also binds and bundles filamentous actin (F-actin) to regulate the spine morphology [9]. Beside these physiological roles, ITPKA plays an important role in the carcinogenesis and metastasis. Down-regulated ITPKA expression was identified in oral squamous cell carcinoma (OSCC) tissues and OSCC cell lines [10]. Whereas in contrast, recent studies on lung cancer showed that high expression of ITPKA was detected in primary tumors and the matched lymph node metastases [11]. Furthermore, the analysis of RNAseq data for kidney renal clear cell carcinoma patients showed that up-regulated ITPKA expression was associated with advanced stage and lower survival rates [12]. Taken together, we hypothesize that ITPKA may be a useful metastasis and prognostic marker for HCC.

In the present study, we investigated the expression levels of ITPKA in HCC and their paired adjacent nontumorous tissues, and further evaluated the correlation of ITPKA expression with clinical parameters and its prognostic value in $\mathrm{HCC}$.

\section{Methods}

\section{Patients and tissue samples}

One hundred thirty five paired primary HCC tumor and nontumorous tissue samples were collected immediately after surgery resection at Sun Yat-sen University Cancer Center between December 2003 and September 2009. The enrollment criteria were as follows: (a) definitive HCC diagnosis by pathology based on WHO criteria; (b) no preoperative trans-hepatic arterial chemoembolization or chemotherapy or radiotherapy before surgery; (c) surgical resection, defined as complete resection of all tumor nodules with the cut surface being free of cancer by histologic examination; (d) complete clinicopathologic and follow-up data. Ethical approval for this study was granted by the Medical Ethics Committee of Sun Yat-sen University Cancer Center. All patients signed informed consent. In this study, nontumoral liver tissues were defined as $2.0 \mathrm{~cm}$ from the tumor margin, which had been described previously [13]. Hepatitis B history was defined as history with positive serum hepatitis B surface antigen (HBsAg). Tumor encapsulation was defined as the presence of a clear fibrous sheath around the tumor at gross inspection. Tumor differentiation was based on the Edmondson and Steiner classification. HCC metastasis was defined as the presence of vascular invasion in the portal vein or the presence of satellite nodules surrounding a larger main tumor [14]. Tumor staging was determined according to the 7 th edition tumor-node-metastasis
(TNM) classification of the American Joint Committee on Cancer.

\section{Cell lines and culture conditions}

HCC cell lines BEL7402, Hep3B, PLC8024, QSG7701, QGY7703, SMMC7721 and immortalized liver cell line LO2 were obtained from the Institute of Virology, Chinese Academy of Medical Sciences (Beijing, China). Huh7 was purchased from American type culture collection (ATCC, Manassas, Virginia, USA). Cells were maintained in high-glucose DMEM (Gibco BRL, Grand Island, NY) supplemented with $10 \%$ fetal bovine serum (FBS) (Gibco BRL, Grand Island, NY). The cells were incubated at $37{ }^{\circ} \mathrm{C}$ in a humidified incubator containing $5 \% \mathrm{CO}_{2}$.

\section{Quantitative real-time reverse transcription polymerase chain reaction (qRT-PCR)}

All fresh tumorous and nontumorous tissue samples were immediately stored at dry ice after resection and then frozen at $-80{ }^{\circ} \mathrm{C}$. Total RNA was extracted from clinical samples or cell lines using TRIzol reagent (Invitrogen), and was reverse-transcribed using an Advantage RT-for-PCR Kit (Clontech Laboratories) according to the manufacturer's instructions. qRT-PCR was performed to detect levels of the corresponding glyceraldehyde-3phosphate dehydrogenase (GAPDH) and ITPKA using a SYBR Green PCR Kit (Applied Biosystems) and LightCycler480 384-well PCR system (Roche Diagnostics). The GAPDH was used as an internal control for ITPKA. Primers for ITPKA are 5'-CCTTTCCACCTC GTCGGTCT-3' (forward) and 5'-GCCTTAAAACT CCCAGTGTGC-3' (reverse). Primers for GAPDH are 5'ACTTCAACAGCGACACCCACTC-3' (forward) and 5'-TACCAGGAAATGAGCTTGACAAAG-3' (reverse). The value of relative expression for each sample was averaged and compared using the $\mathrm{Ct}$ method. $\Delta \Delta \mathrm{Ct}($ sample $)=$ $\Delta \mathrm{Ct}$ (sample) $-\Delta \mathrm{Ct}$ (calibrator), $\Delta \mathrm{Ct}$ (sample) $=\mathrm{Ct}$ (sample) of ITPKA - Ct(sample) of GAPDH; $\triangle \mathrm{Ct}$ (calibrator) $=\mathrm{Ct}$ (calibrator) of ITPKA - Ct(calibrator) of GAPDH; calibrator was defined as the pooled samples from 135 adjacent nontumorous tissues.

\section{Western blot analysis}

ITPKA protein expression in cell lines was detected by Western blotting. Briefly, cells were washed twice with ice-cold PBS. Total protein was extracted with lysis buffer for $45 \mathrm{~min}$ on ice. Equal amounts of protein were separated by $12 \%$ SDS-PAGE and electrophoretically transferred to polyvinylidene difluoride membranes (Millipore) using a mini trans-blot apparatus (Bio-Rad Laboratories). Membranes were blocked with PBS-0.05\% Tween 20 containing $5 \%$ nonfat dry milk for one hour at room temperature and incubated with 
polyclonal rabbit anti-ITPKA (1:1,000; Proteintech) or monoclonal mouse anti-GAPDH antibody (1:5,000; Vazyme Biotech) at $4{ }^{\circ} \mathrm{C}$ overnight. Membranes were then washed three times with PBS-0.05\% Tween 20 and incubated with horseradish peroxidase-conjugated goat anti-rabbit or anti-mouse IgG (Santa Cruz Biotechnology) at a 1:5,000 dilution for one hour at room temperature. Blots were developed using an enhanced chemiluminescence kit (Pierce). Each experiment was repeated at least three times.

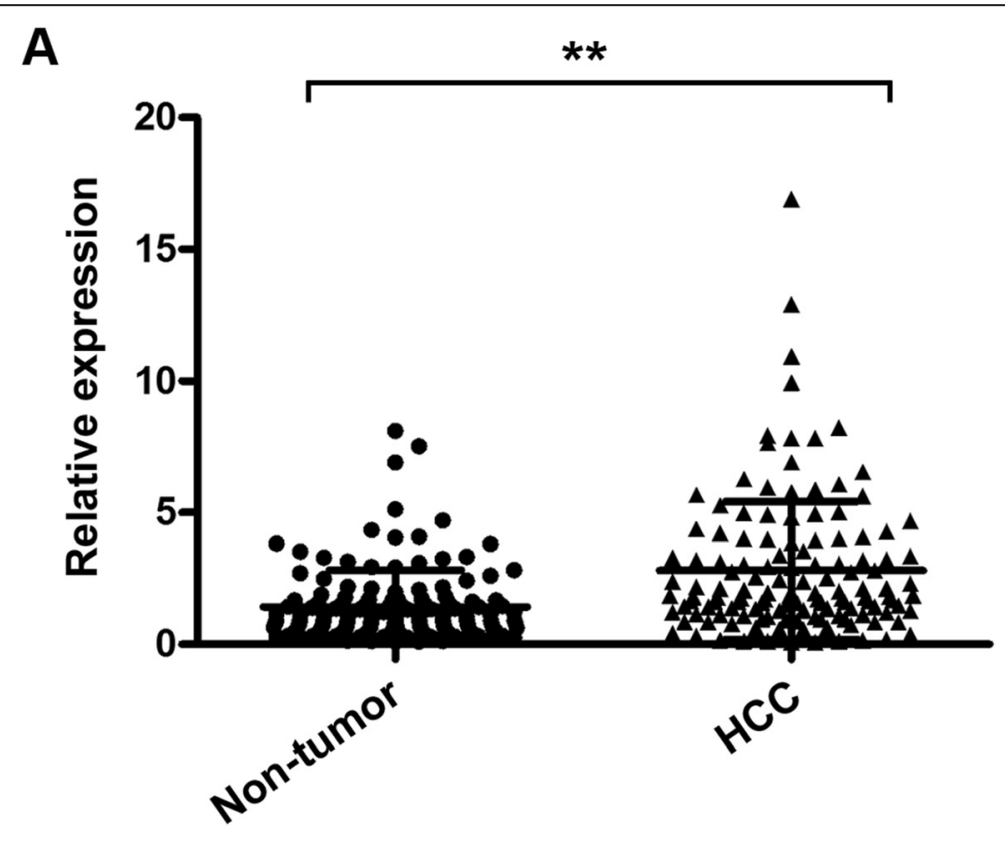

B

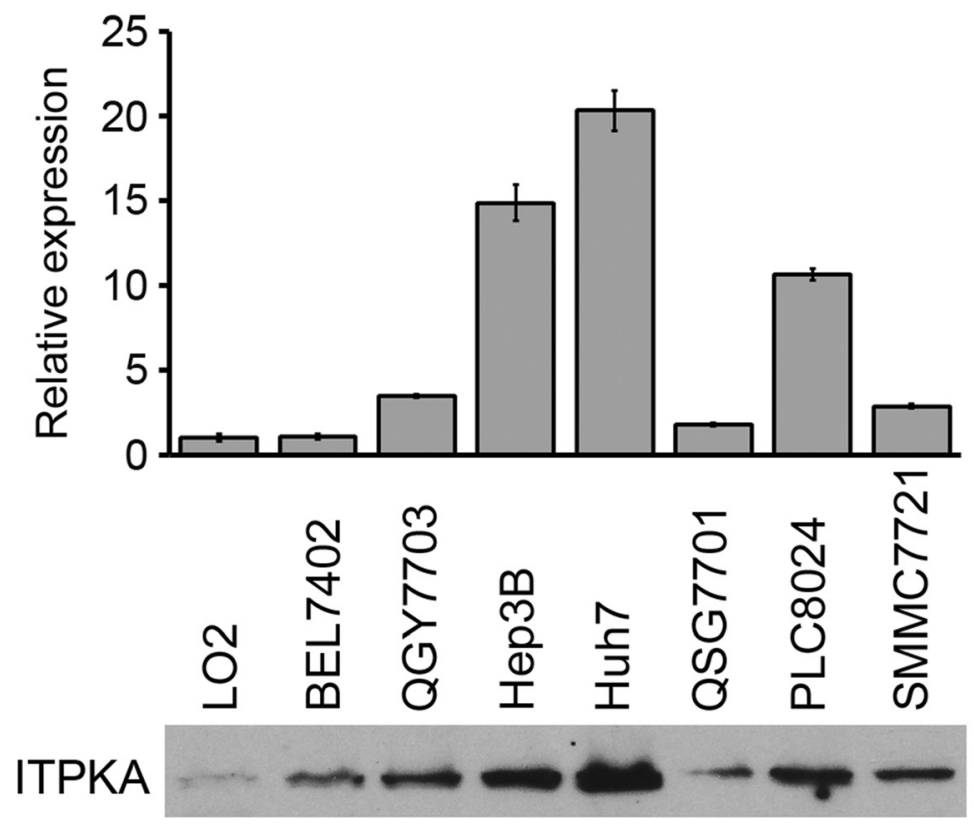

GAPDH

Fig. 1 ITPKA was up-regulated in HCCS. a ITPKA mRNA was markedly increased in tumor tissues than that in the paired adjacent nontumor tissues. **, $P<0.001$, paired $t$-test. $\mathbf{b}$ Up-regulation of ITPKA was detected in 4 of 7 HCC cell lines by qRT-PCR (upper) and western blot analysis (lower). Immortalized liver cell line (LO2) was used as control 


\section{Statistical analysis}

All statistical analyses were performed using the Statistical Package for the Social Sciences (SPSS) version 16.0 (SPSS Inc, Chicago, IL). Paired two-tailed student's $t$ test was used to compare the expression of ITPKA in primary $\mathrm{HCC}$ tumors and their corresponding adjacent nontumorous tissues. The correlation between ITPKA expression and clinicopathological parameters was assessed by chi-square test or Fisher's exact test. Disease-specific survival was calculated from the time of surgery to either the time of death from HCC or last follow up (31 December 2014). The prognostic value was calculated by the Kaplan-Meier analysis with log-rank test. Univariate and multivariate survival analysis was performed using the Cox proportional hazard model with a forward stepwise procedure (the entry and removal probabilities were 0.05 and 0.10 , respectively). A significant difference was considered statistically when $P$ value was $<0.05$.

\section{Results}

ITPKA expression was up-regulated in HCC

Our prior RNA-seq profiling data showed that ITPKA was overexpressed in all ten tested HCC tumor tissues. High expression of ITPKA (defined as $>2$-fold change) was detected in 66 of 135 (48.9\%) of HCC tissues by qRT-PCR, compared with their normal counterparts. The average level of ITPKA expression in tumor tissues was significantly higher than that in non-tumor tissues (1.11 versus $3.01, P<0.001$, paired Student's $t$ test; Fig. 1a). The median fold change of ITPKA (1.84) in HCC tumor tissues was used as a cutoff value to divide all 135 patients into two groups: the high expression group $(n=66)$ and the low expression group $(n=69)$. The expression levels of ITPKA in seven HCC cell lines and one immortalized liver cell line (LO2) were tested by qRT-PCR and western blot analysis. Compared with LO2, up-regulation of ITPKA was detected in QGY7703, Hep3B, Huh7 and PLC8024 cells (Fig. 1b).

\section{Clinicopathologic features of ITPKA in HCC patients}

The correlation between ITPKA mRNA expression in primary $\mathrm{HCC}$ and clinicopathological features was summarized in Table 1. High expression of ITPKA was significantly associated with vascular invasion $(P=0.001)$ and TNM stage $(P=0.005)$. No correlation was observed between ITPKA expression and other clinicopathological characteristics.

\section{Association between ITPKA expression and patient survival}

Univariate analysis showed that HBsAg, serum AFP level, tumor size, tumor number, vascular invasion, TNM stage,
Table 1 Association of ITPKA expression with clinicopathological features in HCCS

\begin{tabular}{|c|c|c|c|c|}
\hline \multirow[t]{2}{*}{ Clinical features } & \multirow[t]{2}{*}{ Cases } & \multicolumn{2}{|c|}{ ITPKA expression } & \multirow{2}{*}{$\begin{array}{l}P \\
\text { value }\end{array}$} \\
\hline & & low level (\%) & high level (\%) & \\
\hline Age (years old) & & & & 0.945 \\
\hline$\leq 50$ & 63 & $32(50.8 \%)$ & $31(49.2 \%)$ & \\
\hline$>50$ & 72 & 37 (51.4 \%) & $35(48.6 \%)$ & \\
\hline Gender & & & & 1.000 \\
\hline Male & 128 & 65 (50.8\%) & $63(49.2 \%)$ & \\
\hline Female & 7 & $4(57.1 \%)$ & $3(42.9 \%)$ & \\
\hline $\mathrm{HBsAg}$ & & & & 0.201 \\
\hline Negative & 15 & 10 (66.7 \%) & $5(33.3 \%)$ & \\
\hline Positive & 120 & 59 (49.2\%) & $61(50.8 \%)$ & \\
\hline AFP $(\mu \mathrm{g} / \mathrm{L})$ & & & & 0.212 \\
\hline$\leq 25$ & 48 & 28 (58.3\%) & $20(41.7 \%)$ & \\
\hline$>25$ & 87 & 41 (47.1\%) & 46 (52.9\%) & \\
\hline Cirrhosis & & & & 0.569 \\
\hline No & 23 & $13(56.5 \%)$ & $10(43.5 \%)$ & \\
\hline Yes & 112 & $56(50.0 \%)$ & 56 (50.0\%) & \\
\hline Tumor size $(\mathrm{cm})$ & & & & 0.126 \\
\hline$\leq 5$ & 56 & $33(58.9 \%)$ & $23(41.1 \%)$ & \\
\hline$>5$ & 79 & $36(45.6 \%)$ & $43(54.4 \%)$ & \\
\hline Tumor number & & & & 0.116 \\
\hline Solitary & 104 & $57(54.8 \%)$ & 47 (45.2 \%) & \\
\hline Multiple & 31 & 12 (38.7 \%) & 19 (61.3\%) & \\
\hline Tumor encapsulation & & & & 0.455 \\
\hline Complete & 43 & $24(55.8 \%)$ & $19(44.2 \%)$ & \\
\hline None & 92 & 45 (48.9 \%) & 47 (51.1\%) & \\
\hline Vascular invasion & & & & 0.001 \\
\hline Absent & 114 & 65 (57.0 \%) & 49 (43.0\%) & \\
\hline Present & 21 & $4(19.0 \%)$ & $17(81.0 \%)$ & \\
\hline Edmondson-Steiner & & & & 0.106 \\
\hline$|-| \mid$ & 79 & 45 (57.0\%) & $34(43.0 \%)$ & \\
\hline III-IV & 56 & 24 (42.9 \%) & 32 (57.1 \%) & \\
\hline TNM stage & & & & 0.005 \\
\hline I & 93 & 55 (59.1\%) & 38 (40.9\%) & \\
\hline$\|-1\|$ & 42 & 14 (33.3 \%) & 28 (66.7 \%) & \\
\hline
\end{tabular}

Statistical significance $(P<0.05)$ is shown in bold

and ITPKA expression were prognostic factors for OS and RFS (Table 2). The 5-year OS and RFS rate in the high ITPKA expression group were significantly lower than those in the low ITPKA expression group (32.2 and $26.8 \%$ versus 59.2 and $57.7 \%$; Fig. 2a). Considering that the TNM stage was correlated with several clinical indexes (such as tumor size, tumor number, and vascular invasion), we did not introduce it into the multivariate Cox proportional hazard model to avoid potential bias. The 
Table 2 Univariate Cox regression analyses for OS and RFS in HCCS

\begin{tabular}{|c|c|c|c|c|}
\hline \multirow[t]{2}{*}{ Clinical features } & \multicolumn{2}{|l|}{ OS } & \multicolumn{2}{|l|}{ RFS } \\
\hline & $\mathrm{HR}(95 \% \mathrm{Cl})$ & $P$ value & $\mathrm{HR}(95 \% \mathrm{Cl})$ & $P$ value \\
\hline Age & $0.678(0.420-1.096)$ & 0.113 & $0.653(0.409-1.041)$ & 0.073 \\
\hline Gender & $2.297(0.562-9.390)$ & 0.247 & $2.526(0.619-10.316)$ & 0.197 \\
\hline $\mathrm{HBsAg}$ & $3.379(1.061-10.763)$ & 0.039 & $3.581(1.126-11.394)$ & 0.031 \\
\hline AFP & $2.187(1.246-3.839)$ & 0.006 & $2.000(1.171-3.418)$ & 0.011 \\
\hline Cirrhosis & 1.025 (0.549-1.916) & 0.937 & $1.127(0.605-2.097)$ & 0.707 \\
\hline Tumor size & $2.161(1.279-3.653)$ & 0.004 & $1.870(1.135-3.081)$ & 0.014 \\
\hline Tumor number & $2.475(1.488-4.118)$ & $<0.001$ & $2.576(1.574-4.216)$ & $<0.001$ \\
\hline Tumor encapsulation & $0.674(0.392-1.161)$ & 0.155 & $0.722(0.429-1.215)$ & 0.221 \\
\hline Vascular invasion & $6.074(3.449-10.698)$ & $<0.001$ & $5.722(3.236-10.119)$ & $<0.001$ \\
\hline Edmondson-Steiner & $1.348(0.832-2.186)$ & 0.225 & $1.296(0.810-2.074)$ & 0.279 \\
\hline TNM stage & 4.919 (3.014-8.082) & $<0.001$ & $4.282(2.654-6.907)$ & $<0.001$ \\
\hline ITPKA expression & $2.579(1.567-4.245)$ & $<0.001$ & 2.669 (1.638-4.349) & $<0.001$ \\
\hline
\end{tabular}

$H R$ hazard ratio; $\mathrm{Cl}$ confidence interval; statistical significance $(P<0.05)$ is shown in bold

multvariate analysis demonstrated that ITPKA expression, HBsAg and vascular invasion were independent prognostic predictors for RFS (Table 3). Further, in a stratified survival analysis according to the TNM stage or serum AFP level, we found that the prognostic significance of ITPKA was retained in TNM stage I $(P=0.001)$, normal AFP level $(\leq 25 \mu \mathrm{g} / \mathrm{L} ; P=0.047)$ and high AFP level ( $>25 \mu \mathrm{g} / \mathrm{L} ; P=0.001)$ subgroups (Fig. $2 \mathrm{~b}$ and $\mathrm{c}$ ).

\section{Discussion and conclusions}

The intracellular second messenger $\operatorname{Ins}(1,4,5) \mathrm{P}_{3}$ controls many different cellular functions by regulating internal $\mathrm{Ca}^{2+}$ signals [7]. The lifetime of $\operatorname{Ins}(1,4,5) \mathrm{P}_{3}$ is tightly regulated by two mechanisms: phosphorylation via ITPKs to $\operatorname{Ins}(1,3,4,5) \mathrm{P}_{4}$ or dephosphorylation via $\operatorname{ins}(1,4,5) \mathrm{P}_{3}$ 5-phosphatase (INPP5A) to inositol 1,4bisphosphate $\left(\operatorname{Ins}(1,4) \mathrm{P}_{2}\right)[15,16]$. ITPKA is the most highly characterized ITPKs isoform, and found upregulated in lung cancer tumor tissues [11]. In the present study, our data demonstrated that $48.9 \%$ of HCC patients showed elevated ITPKA expression in their tumorous specimens compared with their normal counterparts. However, down-regulation of ITPKA was found in oral squamous cell carcinoma, suggesting that ITPKA may serve as a tumor-suppressor [10]. Based on these studies, the function of ITPKA seems to depend on its cellular context.

We next investigated the clinicopathologic correlation of ITPKA expression in HCC patients. The results showed that overexpression of ITPKA correlated with vascular invasion $(P=0.001)$ and TNM stage $(P=0.005)$, which strongly suggested that ITPKA was involved in the metastasis and progression of HCC. This is in an agreement with two recent studies, which showed that ectopic expression of ITPKA enhanced the metastatic potential of tumor cells $[11,17] . \mathrm{Ca}^{2+}$ is a ubiquitous second messenger that mediates numerous cellular processes, including cell proliferation, survival, apoptosis, migration and gene expression. Increases of intracellular $\mathrm{Ca}^{2+}$ concentration have long been known to be involved in cell migration and invasion. $\operatorname{Ins}(1,4,5) \mathrm{P}_{3}$ can bind to the ER membrane $\mathrm{Ca}^{2+}$-permeable Ins $(1,4,5) \mathrm{P}_{3}$ receptor $\left(\mathrm{IP}_{3} \mathrm{R}\right)$ channels, which results in the opening of the membrane channel, and further release the stored $\mathrm{Ca}^{2+}$ into the cytosol $[18,19]$. ITPKA metabolizes $\operatorname{Ins}(1,4,5) \mathrm{P}_{3}$ to $\operatorname{Ins}(1,3,4,5) \mathrm{P}_{4}$, which in turn terminates the signal to release $\mathrm{Ca}^{2+}$ from the endoplasmic reticulum. On the other hand, in some cases the $\operatorname{Ins}(1,3,4,5) \mathrm{P}_{4}$, generated by ITPKA, can protect $\operatorname{Ins}(1,4,5) \mathrm{P}_{3}$ by competitively inhibiting the activity of INPP5A and thus prolongs the effect of $\operatorname{Ins}(1,4,5) \mathrm{P}_{3}$ on $\mathrm{Ca}^{2+}$ signals $[20,21]$. Moreover, a recent report demonstrated that in EGF-stimulated tumor cells Ins $(1,3,4,5) \mathrm{P}_{4}$ prolonged $\mathrm{Ca}^{2+}$ signaling by activation of SOCE [17]. Hence, we speculated that ITPKA might enhance the metastatic potential of HCC cells by increasing intracellular $\mathrm{Ca}^{2+}$ concentration. However, further studies are required to elucidate the function and mechanisms of ITPKA that involved in the $\mathrm{Ca}^{2+}$ signaling in HCC. During metastatic dissemination, cancer cells must acquire the ability to migrate, which is correlated with cytoskeletal remodeling. Independent of its $\mathrm{InsP}_{3}$ kinase activity, ITPKA can modify spine shape and internal microstructure by directly binding and bundling actin filaments and/or by recruiting Rac1 and associated signaling machinery $[9,22]$. It has also been shown that ITPKA induces the formation of filopodiaand lamellipodia-like protrusions, and consequently enhances the migratory and invasive abilities of tumor cells 


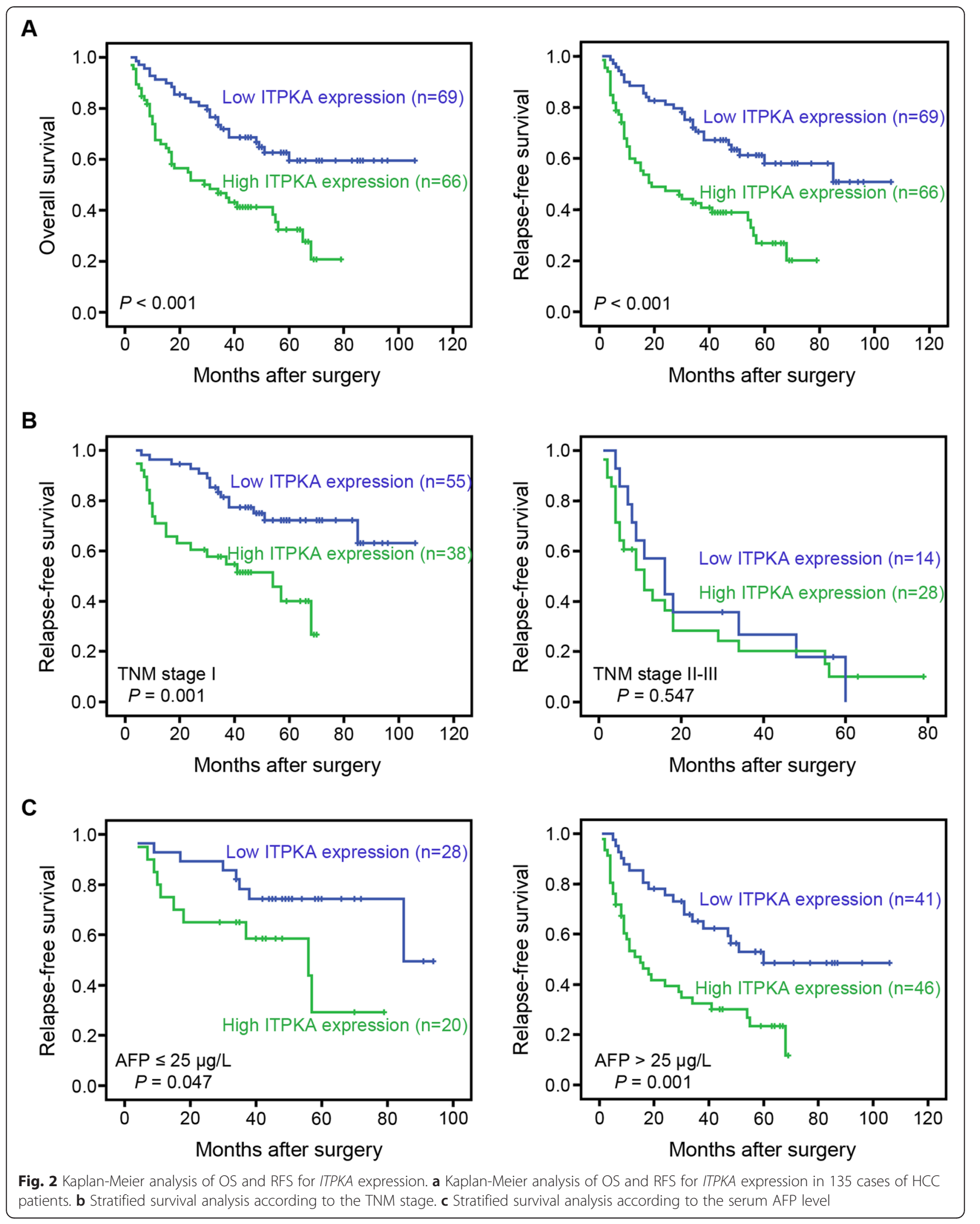


Table 3 Multivariate Cox regression analyses for OS and RFS in HCCS

\begin{tabular}{|c|c|c|c|c|}
\hline \multirow[t]{2}{*}{ Clinical features } & \multicolumn{2}{|l|}{ OS } & \multicolumn{2}{|l|}{ RFS } \\
\hline & $\mathrm{HR}(95 \% \mathrm{Cl})$ & $P$ value & $\mathrm{HR}(95 \% \mathrm{Cl})$ & $P$ value \\
\hline $\mathrm{HBsAg}$ & $3.262(0.999-10.645)$ & 0.050 & $3.330(1.022-10.849)$ & 0.046 \\
\hline AFP & $1.477(0.810-2.695)$ & 0.203 & $1.376(0.777-2.436)$ & 0.273 \\
\hline Tumor size & $1.939(1.106-3.399)$ & 0.021 & $1.624(0.949-2.780)$ & 0.077 \\
\hline Tumor number & $1.348(0.763-2.383)$ & 0.304 & $1.469(0.841-2.566)$ & 0.176 \\
\hline Vascular invasion & $3.325(1.752-6.309)$ & $<0.001$ & $2.917(1.533-5.553)$ & 0.001 \\
\hline ITPKA expression & $1.825(1.064-3.132)$ & 0.029 & $1.868(1.099-3.175)$ & 0.021 \\
\hline
\end{tabular}

$H R$ hazard ratio; $\mathrm{Cl}$ confidence interval; statistical significance $(P<0.05)$ is shown in bold

$[17,23]$. Consequently, the migration-promoting effect of ITPKA is regulated by both enzyme activity-dependent and activity-independent mechanism. Besides, $\operatorname{Ins}(1,3,4,5) \mathrm{P}_{4}$ itself has the potential to regulate various cellular functions by acting on multiple targets, the majority of which contain pleckstrin homology (PH) domains [24]. One of earliest suggested $\operatorname{Ins}(1,3,4,5) \mathrm{P}_{4}$ effectors are channel proteins residing in the plasma membrane. For example, Ins $(1,3,4,5) \mathrm{P}_{4}$ can activate $\mathrm{K}^{+}$channels in the plasma membrane in cooperation with the internal $\mathrm{Ca}^{2+}[25]$. In mouse lacrimal acinar cell, $\mathrm{Ca}^{2+}$-dependent $\mathrm{Cl}$-channel is also implicated as a Ins $(1,3,4,5) \mathrm{P}_{4}$ effector [26]. The second major class of Ins $(1,3,4,5) \mathrm{P}_{4}$ effectors are regulators of the small $\mathrm{G}$ proteins Ras and Rap. Ins $(1,3,4,5) \mathrm{P}_{4}$ plays contradicting roles in different models: Ins $(1,3,4,5) \mathrm{P}_{4}$ promotes the activation of a unique Ras-GAP (GAP1 $\left.1^{\mathrm{IP} 4 \mathrm{BP}}\right)$, and consequently inactivation of the Ras GTPase; or inhibits RASA3 GAP activity by removing RASA3 from the plasma membrane [27-29]. Nevertheless, until now, the components of Ins $(1,3,4,5) \mathrm{P}_{4}$-based signaling systems are far from clear. Further studies are required to define the roles of ITPKA and its products precisely in HCC.

Our study also demonstrated that high expression of ITPKA was one of the most important prognosis factors for OS and RFS in the univariate and multivariate analysis. The 5-year RFS of patients with high ITPKA expression was markedly shorter than that with low expression (26.8 \% versus $57.7 \%$ ). It is known that HCC patients with the same TNM stage, histopathologic features of tumor, and treatment strategy (such as curative resection) may experience quite different clinical outcomes [30]. With the stratified survival analysis according to the TNM stage, we found that the prognostic significance of ITPKA still existed in subgroup of patients in early clinical stage (TNM stage I): the 5-year RFS for ITPKA high expression and low expression patients was $40.0 \%$ versus $72.1 \%(P=0.001)$. AFP is the current gold standard and most commonly used biomarker for the diagnosis and monitoring the effectiveness of treatment or recurrence in HCC patients [31]. Until now, there was no ideal biomarker for monitoring recurrence and metastasis in $\mathrm{HCC}$ patients with normal AFP level after curative resection [32, 33]. Interestingly, we found that ITPKA status could stratified the normal AFP level group into two subgroups with substantially different 5-year RFS (29.3 and $74.2 \%$ for ITPKA high and low patients, respectively; $P=0.047$ ). Given that there were only 48 cases of HCC patients with normal AFP level in the present study, further investigation with a larger sample size is required to confirm this finding.

In conclusion, the results of present study for the first time demonstrated that high expression of ITPKA in $\mathrm{HCC}$ tumorous specimens indicated aggressive tumor behaviors and predicted a poor clinical outcome. These findings suggested that ITPKA may serve as a suitable prognostic marker for HCC patients after surgery, especially in early clinical stage.

\section{Abbreviations}

ITPKA: Inositol-1,4,5-trisphosphate-3-kinase-A; HCC: Hepatocellular carcinoma; OS: Overall survival; RFS: Relapse-free survival; AFP: Alpha-fetoprotein; TNM: Tumor Node Metastasis; RNA-Seq: Transcriptome sequencing; ITPKs: Trisphosphate 3-kinases; Ins(1,4,5) $\mathrm{P}_{3}$ : Inositol 1,4,5-trisphosphate; Ins $(1,3,4,5) \mathrm{P}_{4}$ : Inositol 1,3,4,5-tetrakisphosphate; INPP5A: Ins $(1,4,5) \mathrm{P}_{3} 5$ phosphatase; Ins $(1,4) \mathrm{P}_{2}$ : Inositol 1,4-bisphosphate; $\mathrm{Ca}^{2+}$ : Calcium; Factin: Filamentous actin; OSCC: Oral squamous cell carcinoma; qRTPCR: Quantitative real-time reverse transcription polymerase chain reaction; PH: Pleckstrin homology; GAPDH: Glyceraldehyde-3-phosphate dehydrogenase.

\section{Competing interests}

The authors declare that they have no competing interests.

\section{Authors' contributions}

$J \mathrm{~L}$ and $\mathrm{YHZ}$ carried out the quantitative real-time RT-PCR and western blot analysis and drafted the manuscript; $\mathrm{PH}$ and BZ participated in the quantitative real-time RT-PCR assay and data analysis; JS and XYG designed the study and revised the manuscript. All authors read and approved the final manuscript.

\section{Acknowledgements}

This work was supported by Young Talent Teachers Plan of Sun Yat-sen University (15ykpy33).

\section{Author details}

${ }^{1}$ Sun Yat-sen University Cancer Center, State Key Laboratory of Oncology in South China, Collaborative Innovation Center for Cancer Medicine, Block 2, Room 708, 651 Dongfeng East Road, Guangzhou 510060, China. 2Department of Clinical Oncology, The University of Hong Kong, L10-56, Laboratory Block, 21 Sassoon Road, Hong Kong, China. ${ }^{3}$ Department of 
Colorectal Surgery, The Sixth Affiliated Hospital, Sun Yat-sen University, Guangzhou, China.

Received: 13 June 2015 Accepted: 29 July 2015

Published online: 07 August 2015

\section{References}

1. Sherman M. Hepatocellular carcinoma: epidemiology, risk factors, and screening. Semin Liver Dis. 2005;25(2):143-54. doi:10.1055/s-2005-871194.

2. Schwartz M, Roayaie S, Konstadoulakis M. Strategies for the management of hepatocellular carcinoma. Nat Clin Pract Oncol. 2007;4(7):424-32. doi:10.1038/ncponc0844.

3. Poon RT, Fan ST. Hepatectomy for hepatocellular carcinoma: patient selection and postoperative outcome. Liver Transpl. 2004;10(2 Suppl 1):S39-45. doi:10.1002/lt.20040

4. Parkin DM, Bray F, Ferlay J, Pisani P. Global cancer statistics, 2002. CA Cancer J Clin. 2005;55(2):74-108.

5. Baek KK, Kim JH, Uhm JE, Park SH, Lee J, Park JO, et al. Prognostic factors in patients with advanced hepatocellular carcinoma treated with sorafenib: a retrospective comparison with previously known prognostic models. Oncology. 2011;80(3-4):167-74. doi:10.1159/000327591.

6. Vanweyenberg V, Communi D, D'Santos CS, Erneux C. Tissue- and cell-specific expression of Ins $(1,4,5)$ P3 3-kinase isoenzymes. Biochem J. 1995:306(Pt 2):429-35.

7. Berridge MJ. Inositol trisphosphate and calcium signalling Nature. 1993:361(6410):315-25. doi:10.1038/361315a0.

8. Shears SB. How versatile are inositol phosphate kinases? Biochem J. 2004:377(Pt 2):265-80. doi:10.1042/BJ20031428.

9. Johnson HW, Schell MJ. Neuronal IP3 3-kinase is an F-actin-bundling protein: role in dendritic targeting and regulation of spine morphology. Mol Biol Cell. 2009;20(24):5166-80. doi:10.1091/mbc.E09-01-0083.

10. Kato H, Uzawa K, Onda T, Kato Y, Saito K, Nakashima D, et al. Down-regulation of 1D-myo-inositol 1,4,5-trisphosphate 3-kinase A protein expression in oral squamous cell carcinoma. Int J Oncol. 2006;28(4):873-81.

11. Windhorst S, Kalinina T, Schmid K, Blechner C, Kriebitzsch N, Hinsch R, et al. Functional role of inositol-1,4,5-trisphosphate-3-kinase-A for motility of malignant transformed cells. Int J Cancer. 2011;129(6):1300-9. doi:10.1002/ ijc.25782.

12. Liu Q, Zhao S, Su PF, Yu S. Gene and isoform expression signatures associated with tumor stage in kidney renal clear cell carcinoma. BMC Syst Biol. 2013;7 Suppl 5:S7. doi:10.1186/1752-0509-7-S5-S7.

13. Qiu J, Huang P, Liu Q, Hong J, Li B, Lu C, et al. Identification of MACC1 as a novel prognostic marker in hepatocellular carcinoma. J Transl Med. 2011;9:166. doi:10.1186/1479-5876-9-166.

14. Morimoto O, Nagano H, Sakon M, Fujiwara Y, Yamada T, Nakagawa H, et al. Diagnosis of intrahepatic metastasis and multicentric carcinogenesis by microsatellite loss of heterozygosity in patients with multiple and recurrent hepatocellular carcinomas. J Hepatol. 2003;39(2):215-21.

15. Irvine RF, Lloyd-Burton SM, Yu JC, Letcher AJ, Schell MJ. The regulation and function of inositol 1,4,5-trisphosphate 3-kinases. Adv Enzyme Regul. 2006;46:314-23. doi:10.1016/j.advenzreg.2006.01.009.

16. Erneux C, Govaerts C, Communi D, Pesesse X. The diversity and possible functions of the inositol polyphosphate 5-phosphatases. Biochim Biophys Acta. 1998;1436(1-2):185-99.

17. Windhorst S, Fliegert $R$, Blechner C, Mollmann $K$, Hosseini Z, Gunther T, et al. Inositol 1,4,5-trisphosphate 3-kinase-A is a new cell motility-promoting protein that increases the metastatic potential of tumor cells by two functional activities. J Biol Chem. 2010;285(8):5541-54. doi:10.1074/jbc.M109.047050.

18. Taylor CW, Thorn P. Calcium signalling: IP3 rises again... and again. Curr Biol. 2001;11(9):R352-5.

19. Prevarskaya N, Skryma R, Shuba Y. Calcium in tumour metastasis: new roles for known actors. Nat Rev Cancer. 2011;11(8):609-18. doi:10.1038/nrc3105.

20. Hermosura MC, Takeuchi H, Fleig A, Riley AM, Potter BV, Hirata M, et al. InsP4 facilitates store-operated calcium influx by inhibition of InsP3 5-phosphatase. Nature. 2000;408(6813):735-40. doi:10.1038/35047115.

21. Irvine R. Inositol phosphates: Does IP(4) run a protection racket? Curr Biol. 2001;11(5):R172-4.

22. Kim IH, Park SK, Hong ST, Jo YS, Kim EJ, Park EH, et al. Inositol 1,4,5trisphosphate 3-kinase a functions as a scaffold for synaptic Rac signaling. J Neurosci. 2009;29(44):14039-49. doi:10.1523/JNEUROSCI.2483-09.2009.
23. Windhorst S, Blechner C, Lin HY, Elling C, Nalaskowski M, Kirchberger T, et al. Ins(1,4,5)P3 3-kinase-A overexpression induces cytoskeletal reorganization via a kinase-independent mechanism. Biochem J. 2008;414(3):407-17. doi:10.1042/BJ20080630.

24. Seeds AM, Sandquist JC, Spana EP, York JD. A molecular basis for inositol polyphosphate synthesis in Drosophila melanogaster. J Biol Chem 2004;279(45):47222-32. doi:10.1074/jbc.M408295200.

25. Molleman A, Hoiting B, Duin M, van den Akker J, Nelemans A, Den Hertog A. Potassium channels regulated by inositol 1,3,4,5-tetrakisphosphate and internal calcium in DDT1 MF-2 smooth muscle cells. J Biol Chem. 1991;266(9):5658-63.

26. Morris AP, Gallacher DV, Irvine RF, Petersen $\mathrm{OH}$. Synergism of inositol trisphosphate and tetrakisphosphate in activating $\mathrm{Ca} 2+-$ dependent $\mathrm{K}+$ channels. Nature. 1987;330(6149):653-5. doi:10.1038/330653a0.

27. Cullen PJ, Hsuan JJ, Truong O, Letcher AJ, Jackson TR, Dawson AP, et al. Identification of a specific Ins $(1,3,4,5)$ P4-binding protein as a member of the GAP1 family. Nature. 1995;376(6540):527-30. doi:10.1038/376527a0.

28. Stokes AJ, Shimoda LM, Lee JW, Rillero C, Chang YT, Turner H. Fcepsilon RI control of Ras via inositol $(1,4,5)$ trisphosphate 3-kinase and inositol tetrakisphosphate. Cell Signal. 2006;18(5):640-51. doi:10.1016/ j.cellsig.2005.06.003.

29. Marechal Y, Pesesse X, Jia Y, Pouillon V, Perez-Morga D, Daniel J, et al. Inositol 1,3,4,5-tetrakisphosphate controls proapoptotic Bim gene expression and survival in B cells. Proc Natl Acad Sci U S A. 2007;104(35):13978-83. doi:10.1073/pnas.0704312104.

30. Lee JS, Chu IS, Heo J, Calvisi DF, Sun Z, Roskams T, et al. Classification and prediction of survival in hepatocellular carcinoma by gene expression profiling. Hepatology. 2004;40(3):667-76. doi:10.1002/hep.20375.

31. Daniele B, Bencivenga A, Megna AS, Tinessa V. Alpha-fetoprotein and ultrasonography screening for hepatocellular carcinoma. Gastroenterology. 2004;127(5 Suppl 1):S108-12.

32. Debruyne EN, Delanghe JR. Diagnosing and monitoring hepatocellular carcinoma with alpha-fetoprotein: new aspects and applications. Clin Chim Acta. 2008;395(1-2):19-26. 10.1016/j.cca.2008.05.010.

33. Qin $L X$, Tang $Z Y$. Recent progress in predictive biomarkers for metastatic recurrence of human hepatocellular carcinoma: a review of the literature. J Cancer Res Clin Oncol. 2004;130(9):497-513. doi:10.1007/s00432-004-0572-9.

\section{Submit your next manuscript to BioMed Central and take full advantage of:}

- Convenient online submission

- Thorough peer review

- No space constraints or color figure charges

- Immediate publication on acceptance

- Inclusion in PubMed, CAS, Scopus and Google Scholar

- Research which is freely available for redistribution

Submit your manuscript at www.biomedcentral.com/submit 